\title{
Moyamoya Associated with Down Syndrome: Management Strategies
}

\author{
Eric S. Nussbaum ${ }^{1}$, Patrick Graupman ${ }^{2}$, Leslie Nussbaum ${ }^{2}$ \\ 1. John Nasseff Neuroscience Institute, MN Neurovascular \& Skull Base Surgery, National Brain \\ Aneurysm Center at the John Nasseff Neuroscience Institute, MN Neurovascular \& Skull Base Surgery 2. \\ National Brain Aneurysm Center, St. Paul, MN
}

$\square$ Corresponding author: Eric S. Nussbaum, lnussbaum@comcast.net

Disclosures can be found in Additional Information at the end of the article

\section{Abstract}

Introduction: We describe four patients with Down syndrome and moyamoya who were referred for possible cerebral revascularization. The unique features associated with these cases are presented.

Methods: A retrospective case review of all inpatient and outpatient records and neuroimaging studies was performed.

Results: Three of the four patients were women; all had bilateral moyamoya. Ages ranged from 18 to 34 years. One patient presented with repeated transient ischemic episodes (TIAs) despite antiplatelet therapy. One had repeated "spells" that mimicked complex partial seizures, but seizure activity could not be demonstrated on electroencephalogram. One patient presented with a minor stroke, and the final patient presented with headaches only with no evidence of ischemia. Superficial temporal artery-middle cerebral artery (STA-MCA) bypass was performed in two patients, bilateral in one. One patient underwent bilateral pial synangiosis procedures. One patient was managed with aspirin alone.

Conclusions: Down syndrome may be associated with moyamoya. Patients with Down syndrome who develop symptoms of cerebral ischemia should be evaluated for this condition. Cerebral revascularization may be warranted in selected cases, and results have been favorable in these patients.

Received 02/24/2013 Review began 02/24/2013 Published 02/25/2013

\section{(๑) Copyright 2013}

Nussbaum et al. This is an open access article distributed under the terms of the Creative Commons Attribution License CC-BY 3.0., which permits unrestricted use, distribution, and reproduction in any medium, provided the original author and source are credited.
Categories: Neurosurgery

Keywords: cerebral ischemia, down syndrome, moyamoya, stroke, revascularization

\section{Introduction}

The association between Down syndrome and moyamoya has been previously reported [1-3]. We describe four patients with Down syndrome and moyamoya who were referred for potential cerebral revascularization procedures. Three patients with neurological symptoms and evidence of impaired cerebral blood flow or cerebrovascular reserve on ancillary testing were managed with surgical revascularization. One asymptomatic patient was managed with antiplatelet therapy alone. Outcomes were favorable in all cases.

\section{Case Presentation}

\section{Patients \& methods}




\section{Cureus}

We reviewed in retrospective fashion the inpatient and outpatient records of all patients referred for cerebral revascularization to a busy neurovascular center. Four patients with Down syndrome and moyamoya findings on angiography were identified. Neuroimaging studies including, computerized tomography (CT) scan, magnetic resonance imaging (MRI), CT perfusion, Xenon-enhanced CT, and cerebral angiography were reviewed. Operative records and follow-up clinic notes were reviewed as well.

\section{Results}

All patients had angiographically-documented moyamoya collateral formation in the setting of supraclinoid internal carotid or middle cerebral artery stenosis/occlusion. There were three women and one man. Ages ranged from 18 to 34 years.

The first patient presented with repeated transient ischemic episodes (TIAs) despite antiplatelet therapy. She had suffered a minor stroke during an orthopaedic surgical procedure one year earlier. The patient also suffered from progressively worsening behavioral difficulties, significantly complicating her care. MRI showed evidence of watershed ischemia; CT perfusion demonstrated impaired cerebral perfusion. Cerebral angiography demonstrated bilateral severe moyamoya. The patient underwent bilateral staged STA-MCA anastomosis. The patient's TIAs stopped, and her behavior improved as well.

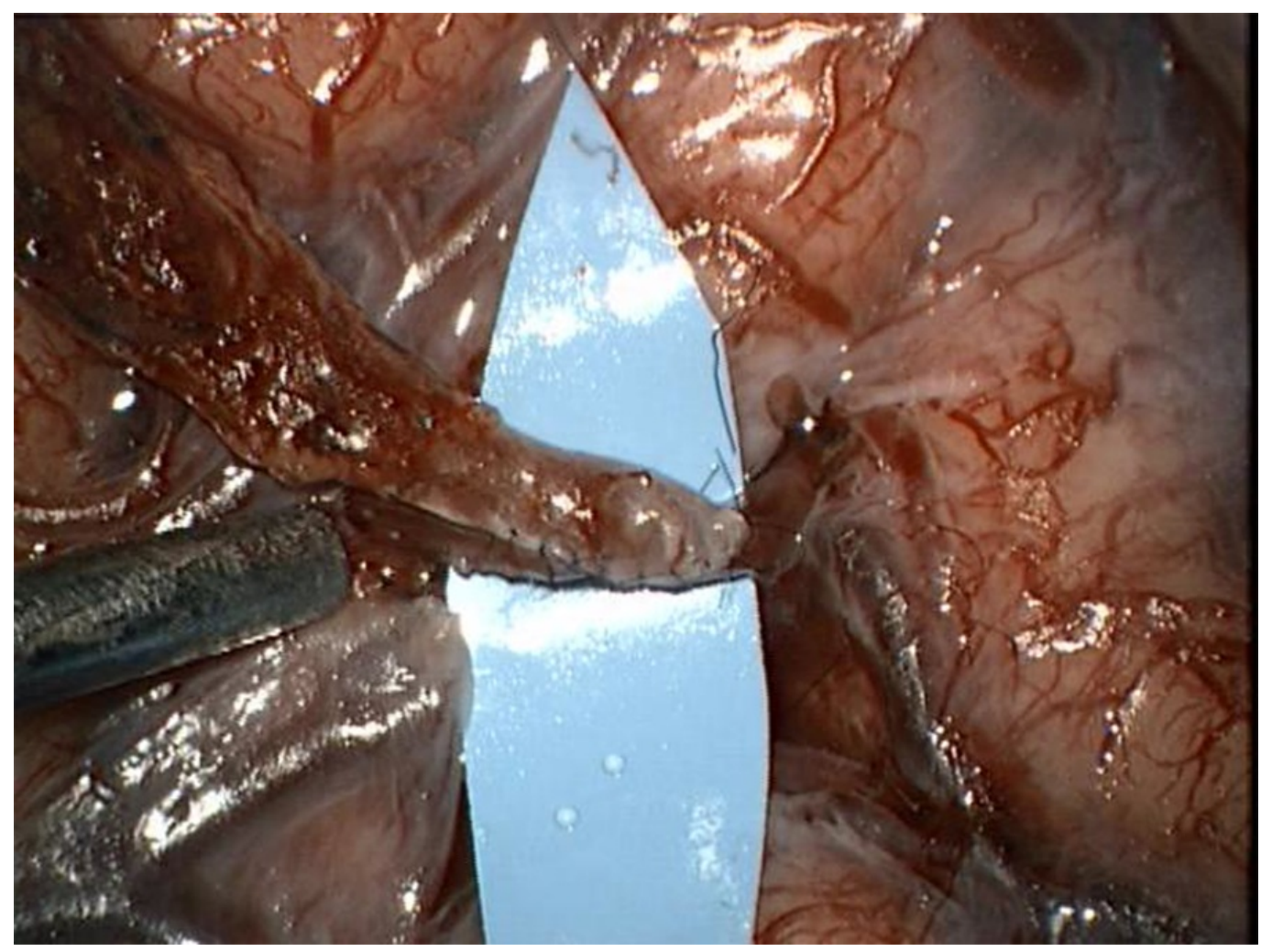

\section{FIGURE 1: Intraoperative photomicrograph revealing a completed STA-MCA anstomosis}

Intraoperative photomicrograph revealing a completed STA-MCA anstomosis. Not the blue background material underneath the recipient cortical MCA branch. The vessel size is approximately $1.2 \mathrm{~mm}$ in this case. 


\section{Cureus}

The second patient presented with repeated "spells" that mimicked complex partial seizures that could not be captured on electroencephalogram. She also exhibited progressive behavioral problems. Cerebral angiography demonstrated bilateral moyamoya, significantly more advanced on the left side. Xenon-enhanced CT with diamox challenge demonstrated poor cerebrovascular reserve on the left, and MRI demonstrated multiple areas of watershed ischemic changes in the left hemisphere. The patient underwent uncomplicated left-sided STAMCA anastomosis. Postoperatively, her spells decreased significantly, and her behavior improved as well, although she continues to have an occasional seizure-like episode.

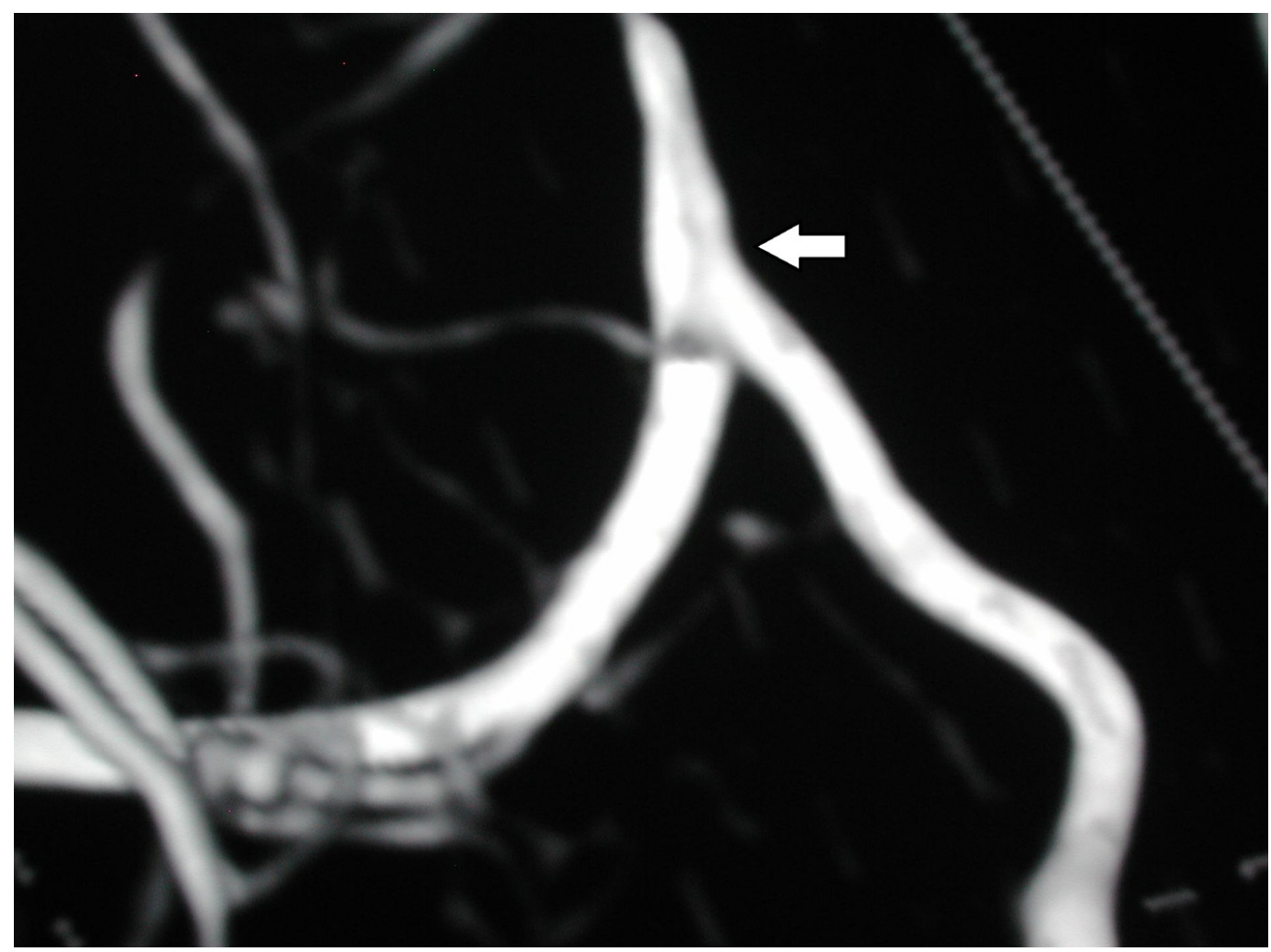

FIGURE 2: Postoperative CT-angiogram reconstruction demonstrating a patent STA-MCA anastomosis (white arrow)

The third patient suffered an ischemic stroke resulting in mild weakness which recovered promptly. MR imaging revealed watershed ischemic changes. He was started on antiplatelet therapy, but given the advanced moya moya changes seen on angiography, a decision was made to proceed with bilateral pial synangiosis. At six month follow-up, he remained at his neurological baseline with no further ischemic symptoms.

The final patient presented with headaches only. MRI suggested the presence of moyamoya, and this was confirmed by angiography. The patient had no evidence of neurological symptoms referable to the moyamoya. There was no history of TIA. CT perfusion demonstrated adequate collateral supply to the involved territories. This patient was managed with aspirin therapy. She has remained asymptomatic during a three year follow-up period.

\section{Discussion}

Patients with Down syndrome are at risk for cerebral ischemia for a variety of reasons [3]. One rare cause of stroke in this population is the unusual association of moyamoya with Down 
syndrome. Although intracerebral and subarachnoid hemorrhage have been reported in older patients with moyamoya, the majority of pediatric and young adult patients with Down and moyamoya have presented with cerebral ischemic symptoms $[2,4,5]$.

The reason for the association between these two disorders remains unclear. It has been suggested that there may be some hypercoagulable state possibly related to protein C deficiency in some Down patients that may be related to the development of moyamoya or other vascular occlusions $[6,7]$. Alternatively, it has been suggested that an autoimmune problem may develop in some Down patients predisposing them to moyamoya development [8]. Finally, it has been postulated that a protein encoded on chromosome 21 may be related to the pathogenesis of moyamoya, explaining the coexistence of the two disorders in some patients [1].

The management of patients with Down and moyamoya is complicated. These patients often have some compromise in their baseline level of functioning which may complicate neurologic assessment. Two of our patients suffered from progressively worsening behavioral difficulties. It was impossible to know for sure whether this issue was related to cerebrovascular insufficiency. Nevertheless, behavioral improvement postoperatively suggested that this may have been at least partially related to the moyamoya.

In addition, patients with Down are subject to other anatomical disorders that may complicate their management. Down patients frequently have cardiac anomalies that may complicate surgical intervention. Similarly, the potential for atlanto-axial instability must not be overlooked in these patients [9]. For these reasons, we have employed preoperative cardiac evaluation as well as flexion-extension cervical spine films as routine preoperative measures in this patient population. Like all patients with moyamoya, it is critical that the anesthesiologist managing the patient intraoperatively avoid hypotension and hyperventilation to prevent intraoperative cerebral ischemic injury.

\section{Conclusions}

Down syndrome may be associated with moyamoya. Patients with Down syndrome who develop symptoms of cerebral ischemia should be evaluated for this condition. Cerebral revascularization may be warranted in selected cases, and results have been favorable in these patients. Specific issues associated with Down syndrome such as an increased potential for associated cardiac anomalies and for atlanto-axial instability must be considered when managing these patients.

\section{Additional Information \\ Disclosures}

Human subjects: Consent was obtained by all participants in this study. Conflicts of interest: In compliance with the ICMJE uniform disclosure form, all authors declare the following: Payment/services info: All authors have declared that no financial support was received from any organization for the submitted work. Financial relationships: All authors have declared that they have no financial relationships at present or within the previous three years with any organizations that might have an interest in the submitted work. Other relationships: All authors have declared that there are no other relationships or activities that could appear to have influenced the submitted work.

\section{References}

1. Cramer SC, Robertson RL, Dooling EC, Scott RM: Moyamoya and Down syndrome. Clinical 


\section{Cureus}

and radiological features. Stroke. 1996, 27:2131-5. 10.1161/01.STR.27.11.2131

2. Dai AI, Shaikh ZA, Cohen ME: Early onset Moyamoya syndrome in a patient with Down syndrome: case report and review of the literature.. J Child Neurol. 2000, 15:696-9. 10.1177/088307380001501012

3. Pearson E, Lenn NJ, Cail WS: Moyamoya and other causes of stroke in patients with Down syndrome. Ped Neurol. 1985, 1:174-9. 10.1016/0887-8994(85)90060-8

4. Aylett SE, Britton JA, De Sousa CM: Down syndrome and moyamoya disease: presentation with subarachnoid hemorrhage. Ped Neurol. 1996, 14:259-61. 10.1016/0887-8994(96)00022-7

5. Nagasaka T, Shiozawa Z, Kobayashi M, et al: Autopsy findings in Down's syndrome with cerebrovascular disorder.. Clinical Neuropath. 1996, 15:145-9.

6. Del-Rio Camacho G, Orozco AL, Perez-Higueras A, et al: Moyamoya disease and sagittal sinus thrombosis in a child with Down's syndrome. Pediatric Radiol. 2001, 31:125-8.

10.1007/s002470000313

7. Gururaj A, Hardy D, Al-Gazali LI, et al: Are the strokes in moya moya syndrome associated with Down syndrome due to protein C deficiency? Brain \& Development. 2002, 24:719-22. 10.1016/S0387-7604(02)00075-X

8. Leno C, Mateo I, Cid C, et al: : : Autoimmunity in Down's syndrome: another possible mechanism of Moyamoya desease. Stroke. 1998, 29:868-9.

9. Takanashi J, Sugita K, Ishii M, et al: A girl with Down syndrome complicated by moyamoya disease and symptomatic atlanto-axial instability. Brain \& Development. 1993, 25:248-52. 